\title{
Elasto-Plastic-Creep Analysis of Restrained Steel Columns Exposed to Fire
}

\author{
D. J. BAKER and Y. M. XIE
}

Department of Civil \& Building Engineering

Victoria University of Technology, Melbourne, Australia

\begin{abstract}
An analytical model is presented to predict the response of restrained steel columns to elevating temperatures due to fire. A locally heated column was idealised as stub column in series with a spring representing restraint from the structure. The model incorporates thermal, creep and elasto-plastic effects which represents the most important material factors of the behaviour of steel columns when exposed to fire. The significance of these effects at different stages of a fire is clearly identified. Axial deformation due to creep was found to dominate at high load levels, with thermal effects dominating at low load levels. The results obtained will be compared with future experimental testing.
\end{abstract}

KEYWORDS: steel column, elastic-plastic, creep, nonlinear material properties, buckling

\section{NOMENCLATURE}

\begin{tabular}{|c|c|c|c|c|c|}
\hline$A$ & $\mathrm{X}$-sectional area & {$\left[m^{2}\right]$} & $T$ & temperature & {$\left[{ }^{\circ} \mathrm{C}\right]$} \\
\hline$A_{s}$ & surface area per & {$\left[m^{2} / m\right]$} & $t$ & time & [minutes] \\
\hline & unit length & & $V$ & volume & {$\left[m^{3}\right]$} \\
\hline$C_{s}$ & specific heat of steel & {$\left[\mathrm{KJ} / \mathrm{kg}^{\circ} \mathrm{C}\right]$} & $\alpha$ & co-efficient of thermal & expansion \\
\hline$E$ & Young's modulus & {$[\mathrm{Pa}]$} & $\delta$ & deflection & {$[\mathrm{m}]$} \\
\hline$F_{E}$ & emissivity co-efficien & $t[0.5]$ & $\varepsilon$ & strain & \\
\hline$K$ & structure stiffness & {$[\mathrm{MN} / \mathrm{m}]$} & $\sigma$ & stress & {$[\mathrm{Pa}, \mathrm{MPa}]$} \\
\hline$L$ & length & {$[\mathrm{m}]$} & $\rho$ & density of steel & {$[7850 \mathrm{~kg} / \mathrm{m} 3]$} \\
\hline$P$ & axial load & {$[\mathrm{N}]$} & & & \\
\hline \multicolumn{6}{|c|}{ Subscripts } \\
\hline$c$ & creep & & th & thermal & \\
\hline J & furnace & & tot & total & \\
\hline$o$ & initial & & $y$ & yield & \\
\hline & steel & & 20 & ambient temperature - & $20^{\circ} \mathrm{C}$ \\
\hline
\end{tabular}




\section{INTRODUCTION}

Australia has a very good fire safety record, but this has been achieved at high costs for building construction, which are imposed by prescriptive and conservative building regulations. The move toward a rational engineering approach to fire engineering design was advocated during the Warren Centre project [1]. The Centre for Environmental Safety and Risk Engineering (CESARE) at Victoria University of Technology is conducting research into the development of cost effective designs for building fire safety systems, based upon rational engineering analysis. The research described in this paper is a contribution to the research focus of CESARE.

The elimination of passive protection to structural steel members in buildings results in more economical construction, with resultant savings in costs and resources, and benefits for the community at large. The use of unprotected steelwork in carparks has been facilitated by a series of full scale fire tests at BHP Research - Melbourne Laboratories (BHPR-ML) [2].

This concession for carparks was based on the consideration of fire loads, ventilation, and the results of the test program at BHPR-ML, where temperatures within the steelwork were never high enough to cause a problem. However, at higher temperatures and loads the effect of creep and local buckling may become significant. Neglecting the effects of creep and local buckling, particularly creep, is an assumption which has been made in many past studies of steel columns exposed to fire, such as those by Culver et al. [3], Burgess et al. [4], and Olawale and Plank [5]. High temperature creep may not be significant for protected steel columns over the time scale of a fire, but this may not be the case for unprotected steel columns subjected to higher fire loads in smaller compartments, where intense fires may develop; for example in partitioned office or residential accommodation.

Due to the highly nonlinear relationship between temperature, stress and creep, the creep models developed to date have been for constant temperature and constant stress [6], slowly varying temperature and constant stress $[7,8 \& 9]$, or slowly varying stress and constant temperature [8, 9]. Harmathy [8] proposed a method for accounting for both varying temperature and stress by assuming small step variations of stress, with stress remaining constant for 15 minute time intervals between steps. These conditions do not apply to a restrained column in a multi-storey building exposed to fire, where localised heating of columns on one fire-affected level is the most probable outcome, as observed in the Broadgate Phase 8 fire of June 23rd, 1990 [10]. Stress levels in the fire-affected columns will initially increase, due to thermal expansion and restraint from neighbouring cooler structural members, and then decrease at higher temperatures, when plastic/creep strains begin to dominate, and restraint from the structure allows unloading of the column.

In order to take advantage of a possible reduction in passive steel protection in buildings other than carparks, there is therefore a need for an analytical model to predict the deformation with time of columns exposed to fire, incorporating the effects of material yielding and creep, whilst allowing for variations in both temperature and stress in the column. The analytical model detailed in this paper is a one dimensional model developed to investigate inelastic behaviour of steel columns at elevated temperatures, using existing 
material properties models. The model calculates over time the thermal, stress and creep deformations of a column exposed to continually varying stress and temperature in the presence of structural restraint, allowing for interaction between all these variables.

\section{COLUMN ANALYSIS}

The column section used in the analysis was a welded H-column with the cross section $\mathrm{H}$ $331 \times 350 \times 20 \times 28$. The column was modelled as a $500 \mathrm{~mm}$ high stub column, heated locally by the hottest layer of gases adjacent to the fire source, ignoring any temperature gradients in the column, and only allowing axial deformation. This simplification is supported by behaviour observed in the Broadgate Phase 8 fire [10], in which five columns in the vicinity of the fire suffered plastic shortening and exhibited local buckling within $0.3 \mathrm{~m}$ of the top connection.

This behaviour can be reproduced in a finite element model. A $4 \mathrm{~m}$ column of the same dimensions and material properties was first analysed at ambient temperature, and then the column was re-analysed with reduced elastic modulus $\left(0.1 \mathrm{E}_{20}\right.$ to crudely represent $\left.800^{\circ} \mathrm{C}\right)$ in the top $666 \mathrm{~mm}$ of the column. The first analysis resulted in global buckling (see Figure 1a), while the second resulted in local buckling, as observed in the Broadgate Phase 8 fire [10]; see Figure 1b. It is interesting to note that the local buckling load in the second analysis reduced to only $15 \%$ of the original global buckling load.

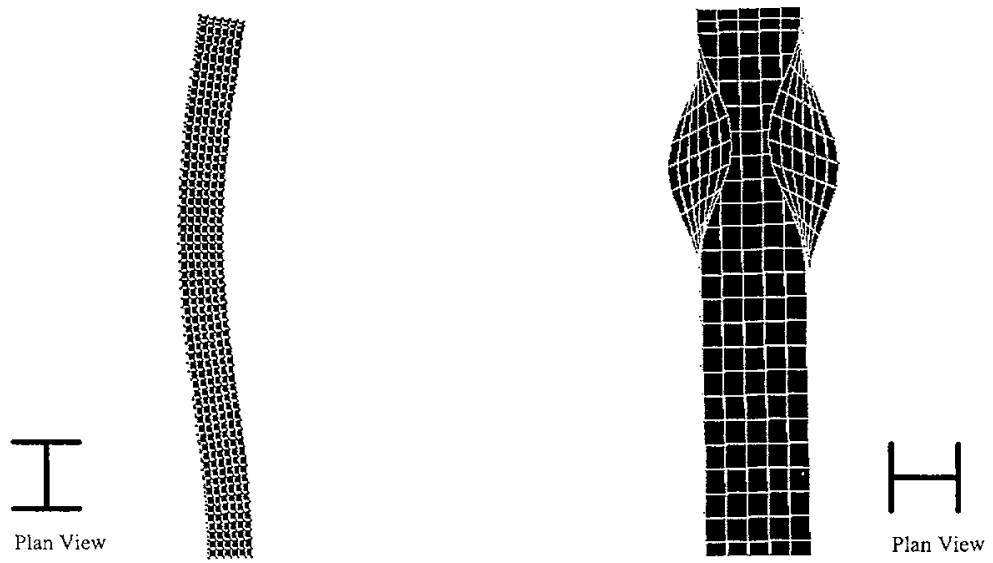

FIGURE 1a. Global Buckling

FIGURE 1b. Local Buckling

\section{MODELS USED IN THE ANALYSIS}

\section{Structural Model}

The column in the analysis was assumed to be an internal column in a ten level structure. One bay of columns and beams were analysed (see Figure $2 a$ ) to determine the equivalent 
structure stiffness $(\mathrm{K})$. This value for the structure stiffness is assumed to remain unchanged throughout the analysis, consistent with the assumption of fire in one level of the building, with the rest of the structure remaining at ambient temperature. The top part of the fire-affected column was then modelled as a stub column in series with a spring representing the structure stiffness; see Figure $2 b$.

Assumptions used in the structural model include

(i) Loading is concentric, with only axial effects allowed.

(ii) No account is taken of Poisson's effect, ie, change in cross-sectional area is negligible.

(iii) Unloading takes place along the stress strain curve for the relevant temperature.

(iv) Residual stresses within the column before loading are ignored.

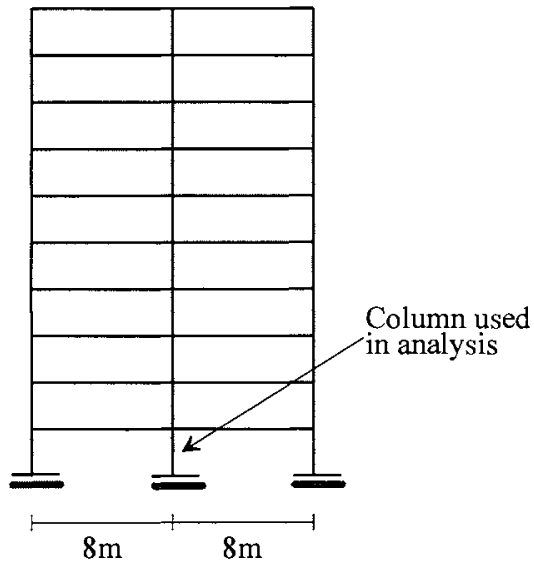

FIGURE 2a. Structural Model

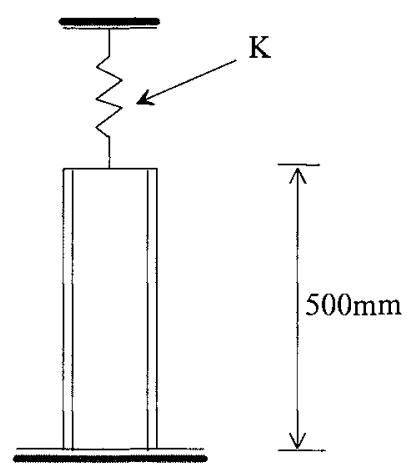

FIGURE 2b. Stub Column Model

\section{Fire Model}

The fire model used in the analysis is the Standard Time-Temperature curve, as specified by Australian Standard AS1530- Part 4 [11]. The time-temperature relationship is given by the following

$T_{f}=T_{f o}+345 \log _{10}(8 t+1)$

This relationship has been used in the testing of barriers, materials, structural elements, etc.

\section{Heat Transfer Model}

The heat transfer model used in the analysis to calculate the temperature in the stub column, is a model reported by Bennetts et al. [12]. The relationship is shown below

$\Delta T / \Delta t=\left(\alpha A_{s} / C_{s} \rho V\right)\left(T_{f}-T_{s}\right)$ 


\section{Material Properties Model}

In the analysis the total strain is assumed to be equal to the addition of thermal, stress and creep related strains, i.e.

$\varepsilon_{t o t}=\varepsilon_{t h}(T)+\varepsilon_{\sigma}(\sigma, T)+\varepsilon_{c}(\sigma, T, t)$

The nonlinear material properties model used in the analysis to describe the stress-strain relationship is that reported by Saab [13], and given by the equations below

$\varepsilon_{\sigma}=\left(\sigma / E_{20}\right)+3 / 7\left(\sigma_{y 20} / E_{20}\right)\left(\sigma / \sigma_{y 20}\right)^{50} \quad 0 \leq T \leq 80^{\circ} C$

$\varepsilon_{\sigma}=\left(\sigma / E_{T}\right)+0.001\left(\sigma / \sigma_{y T}\right)^{n} \quad 80<T \leq 800^{\circ} C$

The variation with temperature of $\sigma_{y T}, E_{T}$ and $n$ are given in Table 1 , below.

TABLE 1. Variation of Co-efficients with Temperature

\begin{tabular}{|l|l|l|l|}
\hline $\begin{array}{l}\text { Temp. Range } \\
\left({ }^{\circ} \mathrm{C}\right)\end{array}$ & $\begin{array}{l}\text { Yield Stress } \\
\left(\sigma_{y T}\right)\end{array}$ & $\begin{array}{l}\text { Elastic Modulus } \\
\left(E_{T}\right)\end{array}$ & \multicolumn{1}{|c|}{} \\
\hline $80 \leq T \leq 400^{\circ} \mathrm{C}$ & $\sigma_{y 20}\left(1.015-0.065 \frac{T}{350}\right)$ & $E_{20}\left(1-2.979\left(\frac{T-20}{1485}\right)^{2}\right)$ & $\frac{4600}{T}+\alpha^{*}, \frac{2650}{T}+\alpha^{\circ}$ \\
\hline $400 \leq T \leq 550^{\circ} \mathrm{C}$ & $\sigma_{y 20}\left(1.7-0.19 \frac{T}{100}\right)$ & $\frac{2400}{T}+\alpha$ \\
\hline $550 \leq T \leq 600^{\circ} \mathrm{C}$ & $\sigma_{y 20}\left(2.97-0.294 \frac{T}{70}\right)$ & $E_{20}\left(1.04-3.15\left(\frac{T-20}{1463}\right)^{2}\right.$ & $\frac{3900}{T}+\alpha$ \\
\hline $600 \leq T \leq 690^{\circ} \mathrm{C}$ & $\sigma_{y 20}\left(1.64-0.099 \frac{T}{50}\right)$ & $"$ & $\frac{3600}{T}+\alpha$ \\
\hline $690 \leq T \leq 800^{\circ} \mathrm{C}$ & $\sigma_{y 20}\left(1.343-0.156 \frac{T}{100}\right)$ & $"$ & $\frac{4600}{T}+\alpha$ \\
\hline
\end{tabular}

${ }^{*} 80 \leq T \leq 200^{\circ} \mathrm{C}$

${ }^{\circ} 200 \leq T \leq 400^{\circ} \mathrm{C}$

$\alpha=T /[500 \ln (T / 1750)]$

The co-efficients in Table 1 differ slightly to those used by Saab, due to curve smoothing required to eliminate discontinuity in both $\sigma_{y T}$ and $E_{T}$ at temperature change points.

\section{Creep Model}

The creep model adopted in the analysis is the creep component of a mechanical model of the elevated temperature behaviour of steel, developed by Fields and Fields [6]. This model incorporates all the parameters involved, namely total time, stress and temperature. The model formulation, based on the Norton-Bailey equation, is given below. (Note: Constants $\mathrm{A}, \mathrm{B}$ and $\mathrm{C}$ are dependent on temperature, chemical composition, manufacturing process, etc)

$\varepsilon_{c}=A t^{B} \sigma^{C}$ 


\section{CALCULATION PROCEDURE}

The calculation procedure, which is illustrated in Figure 3, uses an incremental iterative approach. At each time step, the program calculates:

(i) Furnace temperature, steel temperature and mechanical properties

(ii) Restrained thermal expansion and the corresponding stress increase

(iii) This new stress is used as the first approximation in an iterative procedure to calculate incremental stress and creep deformations, which are added to the restrained thermal expansion. Compatibility of load and total deformation are used, according the structure stiffness, to check for convergence of the load.

Assumptions used in the calculation procedure include:

(i) The behaviour of the column is described by a series of incremental time steps. The temperature and stress are constant at the start and end of each time step, with any changes occurring within the time step.

(ii) The change in thermal deformation at each step is calculated from the change in temperature between each time step.

(iii) The stress related deformation is calculated at each time step, with the total stress related deformation up to the previous time step being subtracted to determine the incremental deformation within the time step.

(iv) The creep related deformation is calculated using the total time, with the steel temperature calculated at time/ 2 , and an average stress, ie, the average of the initial stress at ambient, and the stress at that time increment. The procedure outlined in (iii) above is then followed to calculate incremental and total creep deformation.

\section{RESULTS AND DISCUSSION}

The results of an analysis of the column that is for a range of load levels illustrates the significance of load level to total axial deformation, ie, increasing total deformation with increasing load level; see Figure 4. The thermal, stress and creep related deformations calculated for each load level exhibit the expected pattern of the domination of thermal effects during the early phase, with a gradual increase in stress and creep components, with creep dominating once the temperature exceeds $600^{\circ} \mathrm{C}$; see Figure 5. This pattern corresponds to an initial load increase, followed by unloading. This is particularly the case for the higher load levels ( $\mathrm{P} / \mathrm{Py}=0.4 \& 0.5$ ); see Figure's $4 \& 5$. (Note: TEMPS in the figures refers to steel temperature).

It is interesting to note the reduction in the significance of creep, predicted by the model, at elevated temperature for lower load levels, $(\mathrm{P} / \mathrm{Py}=0.2 \& 0.3)$; compare Figure $5 \& 6$. To determine if creep deformation was actually dominating the deformation due to material yielding at the higher load levels, the column was analysed with the time dependent or creep effects removed. The results are shown in Figure 7, where it appears that the effect of creep is significant for higher load levels at temperatures above $600^{\circ} \mathrm{C}$, but has little effect at lower load levels, where thermal effects dominate up to a temperature of $750^{\circ} \mathrm{C}$, where the analysis was terminated. This is also supported by the non-dimensional plot of yield stress 


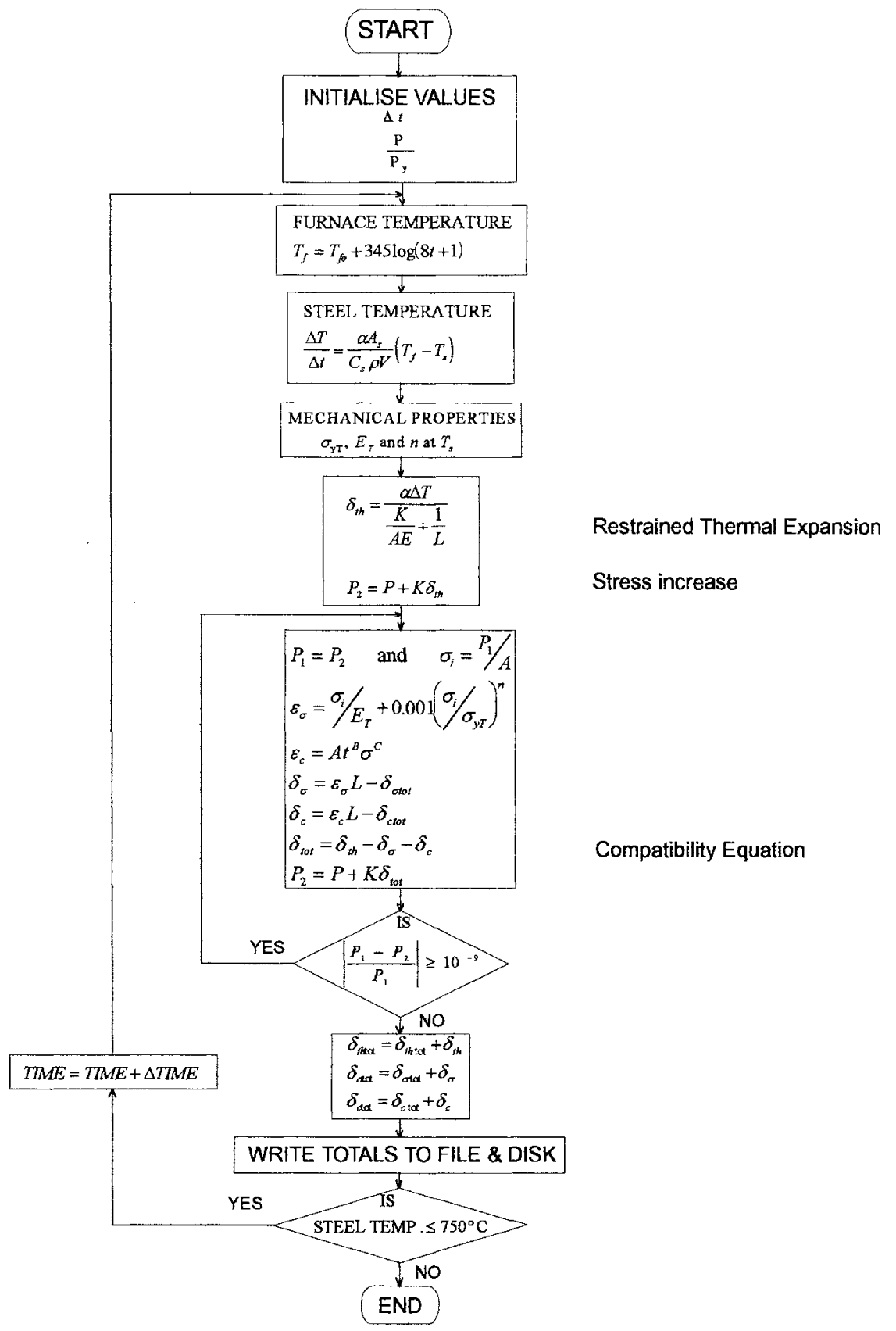

FIGURE 3. Calculation Procedure Flowchart 


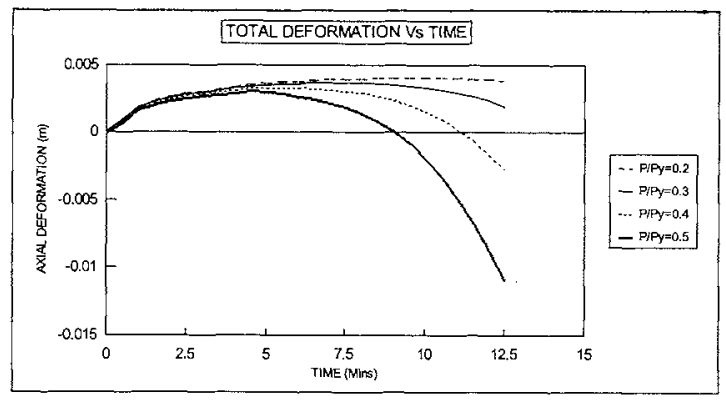

\section{FIGURE 4. Total Deformation Vs Load Level}

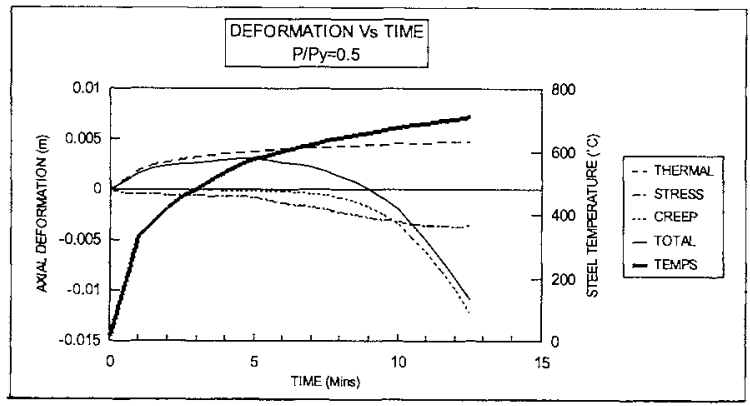

FIGURE 5. Deformation Vs Time - P/Py=0.5

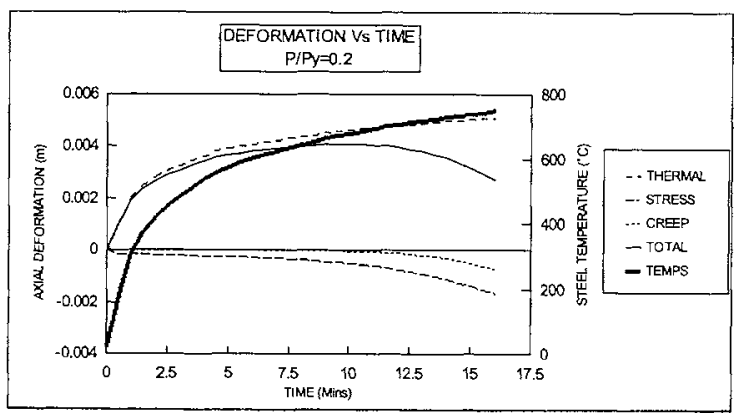

\section{FIGURE 6. Deformation Vs Time $-\mathrm{P} / \mathrm{Py}=0.2$}

at each time, and therefore temperature, also shown in Figure 7 . Total deformation at higher temperatures appears to be at a similar rate to the drop in yield stress for the lower load level, 
whereas for the higher load level, the increase in total deformation is at a greater rate than the drop in yield stress, particularly for the analysis including creep.

The variation in axial load in the column for load levels of 0.5 and 0.2 is shown in Figure 8, where an initial load increase due to thermal expansion is followed by significant unloading of the column for the higher load level, when creep deformation begins to dominate. The stress variation was found to range from $16 \%$ to $24 \%$ of the ambient temperature yield stress, within only a ten minute time period. These relatively large variations in stress over a small time period are outside the range analysed by Harmathy [8] for incorporating varying stress and temperature.

Also included in Figure 8 is a plot yield stress over time. For the 0.2 load level, the rate of change in axial load in the column is always less than the rate of decrease in yield stress.

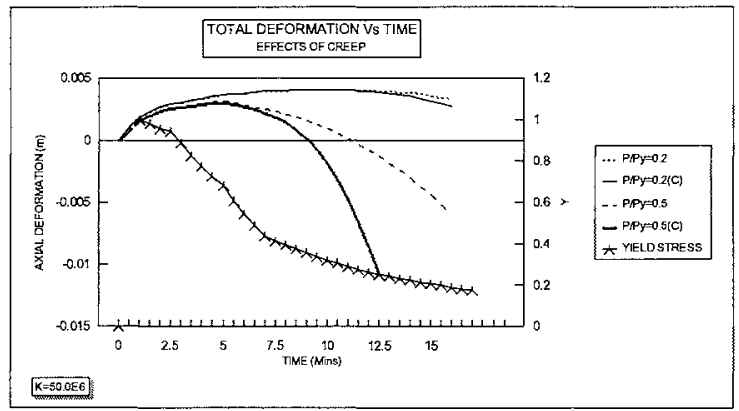

FIGURE 7. Effect of Creep at Varying Load Levels (Note: $(\mathrm{C})$ indicates creep is included)

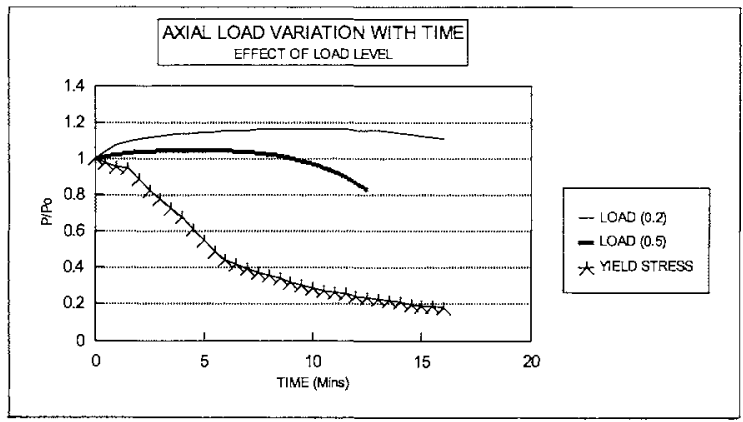

\section{FIGURE 8. Axial Load Variation with Load Level}

However, at higher temperatures for the 0.5 load level, the rate of decrease in axial load in the column appears to be slightly greater than the rate of decrease in yield stress, presumably due 
to the effects of creep, and the associated unloading of the column. Increasing the level of structural restraint results in a slightly decreased total deformation, since higher stiffness in the structure attracts greater load, therefore reducing the load in the column, i.e. absorbing a larger proportion of the thermal effects initially, and allowing greater unloading of the column as stress and creep effects dominate in the latter stages of the fire; see Figure 9.

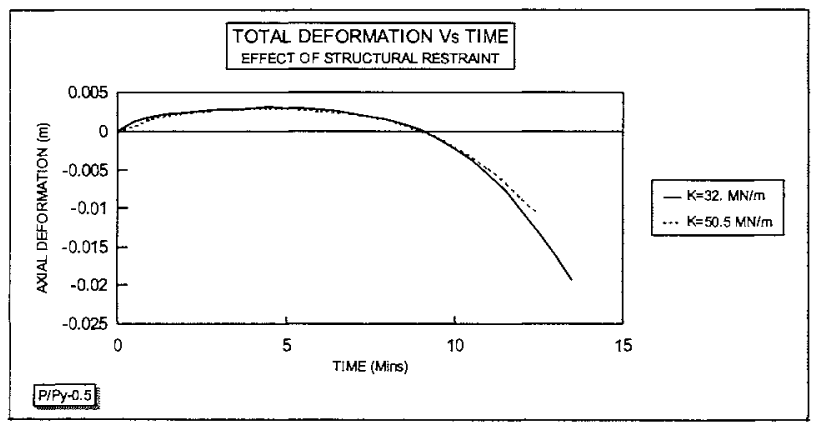

\section{FIGURE 9. Effect of Structural Restraint}

Creep in steel is highly dependent on the chemical composition of the steel, and the manufacturing process used [14]. The Fields and Fields model [6] used in the analysis offers no adjustment for different steels. Data from tests carried out by Skinner [15] on Australian steels was used by Fields and Fields for validation of their model, but this data is from steels of a different chemical composition, and manufactured by different processes, to steel currently used in Australia. The amount of creep implicitly included in the Saab [13] material properties model is uncertain. Figure 5 would indicate, however, that very little is incorporated at high load levels.

The results obtained from this limited analysis are consistent with those obtained by Okabe $e t$ al. [9] in a three-dimensional elasto-plastic-creep analysis with varying temperature and constant stress. Okabe found that creep is not significant at temperatures below $450^{\circ} \mathrm{C}$, and results in deformations 2 to 3 times larger at higher load levels; $c f$. with Figure's 5 and 7 . The model developed in this paper will have to be calibrated to experimental results, however, before any significance can be attached to the values of time and deformation predicted.

\section{FUTURE WORK}

The development of the above analytical model is the first stage of an ongoing project to investigate inelastic behaviour of unprotected steel columns at elevated temperatures. The project will involve extensive testing of stub columns and material properties at BHPR-ML. The results of the material properties testing will be fitted to relationships similar to those of Saab [13], and used to calculate instantaneous stress-strain relationships, while the Fields and Fields creep model [6] will be modified to fit the creep data obtained from the testing. These relationships will then be used in a finite element model, under development, to analyse full 
length restrained columns at elevated temperatures. The model will consider both local and overall buckling, temperature gradients, transient temperature and stress, residual stresses, and eccentric loading. The extensive stub column testing program will be used to validate this analytical model.

\section{CONCLUSIONS}

The simplified one-dimensional analytical model developed allows the analysis of restrained steel columns exposed to a fire, incorporating thermal, stress and creep deformations, with continually varying stress and temperature. The significance of load level and restraint offered by the structure in the axial deformation of the column analysed has been demonstrated.

The axial deformations predicted for lower load levels ( $\mathrm{P} / \mathrm{Py}=0.2$ and 0.3$)$ up to a temperature of $750^{\circ} \mathrm{C}$ are much lower than those observed in the Broadgate Phase 8 fire [10], where significant plastic shortening and local buckling occurred. It was estimated that in the Broadgate fire the maximum load level in the fire-affected columns was $P / P y=0.251$, and the maximum steel temperature $600^{\circ} \mathrm{C}$. This may indicate the significance of local buckling at lower load levels. This is supported by the fact that the standard time-temperature relationship used in this analysis to represent the heating of the column represents much more severe conditions than would be expected in a real fire.

After validation with the testing programs at BHPR-ML, a more comprehensive model will be developed, as detailed above. This model which will become a useful analytical tool for predicting the behaviour of real columns exposed to fire, allowing account to be taken of restraint provided by neighbouring cooler structural elements, with possible advantage being taken of redundancy within the structure.

\section{ACKNOWLEDGMENT}

The authors wish to thank Dr. I.D. Bennetts and Dr. P.H. Dayawansa of BHP Research Melbourne Laboratories and Professor V.R. Beck, Director, Centre for Environmental Safety and Risk Engineering, and $\mathrm{Mr}$ A. Hira, and Mr S.A. Young, Department of Civil and Building Engineering, Victoria University of Technology, for their significant input and support to this project.

\section{REFERENCES}

(1) Warren Centre, "Project Report", Fire Safety and Engineering Project, The Warren Centre for Advanced Engineering, The University of Sydney, December, 1989.

(2) Almand, K. H., Thomas, I.R \& Bennetts, I.D., "Fire in Offices", BHP Melbourne Research Laboratories, MRL/PS69/89/005, Aug. 1989. 
(3) Culver, C., Aggarwal, V. \& Ossenbruggen, P., "Buckling of Steel Columns at Elevated Temperatures", J. of the STRUCTURAL DIVISION, ASCE, April 1973.

(4) Burgess, I. W., Olawale, A. O. \& Plank, R. J., "Failure of Steel Columns in Fire", FIRE SAFETY JOURNAL, Vol 18, No 2, 1992, Pp 183-201.

(5) Olawale, A. O. \& Plank, R. J., "The Collapse Analysis of Steel Columns in Fire Using a Finite Strip Method", INTERNATIONAL JOURNAL FOR NUMERICAL METHODS IN ENGINEERING, Vol 26, 1988, Pp 2755-2764.

(6) Fields, B. A. \& Fields, R. J., "Elevated Temperature Deformation of Structural Steel", NISTIR 88-3899.

(7) Fields, B. A. \& Fields, R. J., "The Prediction of Elevated Temperature Deformation of Structural Steel Under Anisothermal Conditions", NISTIR 4497, January 1991.

(8) Harmathy, T.Z., "A Comprehensive Creep Model", JOURNAL OF BASIC ENGINEERING, ASME, September, 1967.

(9) Okabe, T., Furamura, F., Ave, T. \& Shinohara, Y., "Elastic-Plastic Creep Three-Dimensional Analysis of Steel H-Columns Subjected to High Temperature", FIRE SAFETY SCIENCE - Proceedings of the Third International Sysposium, Ed. Geoffrey Cox \& Brian Langford, Borehamwood, UK, 1991, Pp 741-50.

(10) "Structural Fire Engineering - Investigation of the Broadgate Phase 8 Fire", STRUCTURAL FIRE ENGINEERING, Steel Construction Industry Forum (SCIF), June 1991.

(11) Australian Standard 1530 - Part 4, "Fire Resistance Tests of Elements of Building Construction", Standards Australia, 1985.

(12) Bennetts, I.D, Thomas, I.R \& Proe, D.J., "Thermal Response of Steel Members Under Fire Test Conditions", METAL STRUCTURES CONFERENCE, I.E.Aust., Brisbane, Australia, 18-20th May, 1983, Pp 50-56.

(13) Saab, H.A., "Nonlinear Finite Element Analysis of Steel Frames in Fire Conditions", $\mathrm{PhD}$ Thesis, University of Sheffield, July 1990.

(14) Williams-Leir, G., "Creep of Structural Steel in Fire: Analytical Expressions", FIRE \& MATERIALS, Vol 7, No 2, 1983, Pp 73-78.

(15) Skinner, D.H., "Measurement of High Temperature Properties of Steel", BHP Melbourne Research Laboratory Report, MRL 6/10, May, 1972. 